\title{
Crescimento inicial de cultivares de amendoim (Arachis hypogaea L.) submetidas a densidades de plantio
}

Submetido- 01 ago. $2020 \quad$ Aprovado - 10 set. $2020 \quad$ Publicado - 14 out. 2020

http://dx.doi.org/10.17648/sas.v1i2.92

\begin{abstract}
Graduando em Agronomia - Universidade Federal do Agreste Magno de Lima Mélo $\mathbb{D}$ jmlima.agro@gmail.com.

Graduanda em Agronomia - Universidade Federal Juliene Lariça Ferreira da Silva (D) julienetecinformatica@gmail.com.
\end{abstract}

Doutor em Agronomia - Universidade Federal do Agreste de Pernambuco, e-mail: jeandsonsv@yahoo.com.br.

Graduanda em Agronomia - Universidade Federal do Agreste de Pernambuco, e-mail: sarahalexandrejane@gmail.com.

Engenheira Agrônoma - Universidade Federal Rural de Pernambuco, e-mail: jamillefagundes@hotmail.com.

\section{RESUMO}

A espécie cultivada de amendoim (Arachis hypogaea L.) está entre as principais oleaginosas cultivadas do mundo. Mas, ainda não há informações técnicas sobre cultivares e densidades de plantio para a produção de fitomassa. Neste sentido, objetivou-se avaliar o crescimento inicial de quatro cultivares de amendoim sob efeito de diferentes densidades de plantio. 0 experimento foi conduzido no município de Garanhuns-PE, nos anos agrícolas 2018/2019 em condições de campo. $O$ delineamento adotado foi de blocos ao acaso, com três repetições, em esquema de subparcela de 4X5, sendo quatro cultivares (Runner IAC 886 e IAC 503 de crescimento prostrado e BR1 e TATU ST de crescimento ereto) e submetidas a cinco densidades de plantio (8, 11, 14, 17 e 20 plantas por metro linear), avaliando-se o crescimento inicial em altura (cm), número de folhas e diâmetro $(\mathrm{mm})$ da haste principal aos 28, 35 e 42 dias após a semeadura (DAS). Para o fator qualitativo (cultivares), os dados foram submetidos à análise de variância e as médias comparadas pelo teste de Tukey (significância de 5\%), empregando-se o software SISVAR. Já para o fator quantitativo (densidades), foi utilizada a análise de regressão. Aos 28 e 35 DAS, todas as cultivares aumentaram a sua altura, número de folhas e diâmetro em função do aumento na densidade de plantio, já aos 42 DAS, o diâmetro não se diferenciou entre as cultivares. Aos 35 dias após o plantio, maiores valores de altura, número de folhas e diâmetro de plantas são obtidos com densidades de 17 e 20 plantas m $^{-1}$. 0 diâmetro de cultivares de porte rasteiro não se diferencia com as de porte ereto aos 42 DAS.

Palavras-chave: Altura; Diâmetro; Número de folhas.

\section{Initial growth of peanut cultivars (Arachis hypogaea L.) submitted to planting densities}




\begin{abstract}
The cultivated peanut species (Arachis hypogaea L.) is among the world's largest cultivated oilseeds. However, there is still no technical information on cultivars and planting densities for phytomass production. In this sense, the objective was to evaluate the initial growth of four peanut cultivars under different planting densities. The experiment was conducted in the municipality of Garanhuns-PE, in the agricultural years 2018/2019 under field conditions. The design adopted was randomized blocks, with three replications, in a $4 \times 5$ subplot scheme, with four cultivars (Runner IAC 886 and IAC 503 prostrate and BR1 and TATU ST standing erect) and submitted to five planting densities $(8,11,14,17$ and 20 plants per linear meter). The initial growth in height $(\mathrm{cm})$, number of leaves and diameter $(\mathrm{mm})$ of the main stem at 28, 35 and 42 days after sowing were evaluated. For the qualitative factor (cultivars), the data were submitted to analysis of variance and the means were compared by the Tukey test (significance of 5\%), using SISVAR software. For the quantitative factor (densities), the regression analysis was used. At 28 and 35 DAS, all cultivars increased their height, number of leaves and diameter as a function of the increase in planting density, already at 42 DAS, the diameter did not differentiate between the cultivars. At 35 days after planting, higher values of height, number of leaves and diameter of plants are obtained with densities of 17 and 20 plants $\mathrm{m}^{-1}$. The diameter of low growing cultivars does not differ with those of erect size at 42 DAS.
\end{abstract}

Keywords: Height; diameter; Number of leaves.

\title{
Crecimiento inicial de cultivares de maní (Arachis hypogaea L.) sometidos a densidades de plantación
}

\section{RESUMEN}

La especie cultivada de maní (Arachis hypogaea L.) se encuentra entre las principales semillas oleaginosas cultivadas en el mundo. Sin embargo, todavía no hay información técnica sobre cultivares y densidades de siembra para la producción de fitomasa. En este sentido, el objetivo fue evaluar el crecimiento inicial de cuatro cultivares de maní bajo el efecto de diferentes densidades de siembra. El experimento se realizó en el municipio de Garanhuns-PE, en los años agrícolas 2018/2019 en condiciones de campo.El diseño adoptado fue de bloques al azar, con tres repeticiones, en un esquema de subparcelas de $4 \times 5$, con cuatro cultivares (Runner IAC 886 e IAC 503 de crecimiento postrado y BR1 y TATU ST de crecimiento vertical) y sometido a cinco densidades de plantación $(8,11,14,17$ y 20 plantas por metro lineal), evaluando el crecimiento inicial en altura $(\mathrm{cm})$, número de hojas y diámetro $(\mathrm{mm})$ del tallo principal a los 28 , 35 y 42 días después de la siembra (DAP). Para el factor cualitativo (cultivares), los datos fueron sometidos a análisis de varianza y las medias comparadas por la prueba de Tukey (significancia del 5\%), utilizando el software SISVAR. Para el factor cuantitativo (densidades), se utilizó el análisis de regresión. A los 28 y 35 DAP, todos los cultivares aumentaron su altura, número de hojas y diámetro debido al aumento en la densidad de siembra, mientras que a 42 $D A P$, el diámetro no difirió entre los cultivares. A los 35 días después de la plantación, se obtienen valores más altos de altura, número de hojas y diámetro de la planta con densidades de 17 y 20 plantas $m^{-1}$. El diámetro de los cultivares de bajo crecimiento no es diferente con los vertical a 42 DAP.

Palabras clave: Altura; Diámetro; Número de hojas.

\section{Introdução}

Pertencente à família Fabaceae, a espécie cultivada de amendoim (Arachis hypogaea L.) originada da América está entre as principais 
oleaginosas cultivadas do mundo. O Continente Asiático é o maior produtor de amendoim sendo a China o principal produtor e consumidor de seus produtos e derivados (IEA, 2018). De acordo com a Companhia Nacional de Abastecimento (CONAB, 2019), a produtividade brasileira de de grãos de amendoim na safra 2018/19 foi de $2.962 \mathrm{~kg} \mathrm{ha}^{-1}$, sendo a região Sudeste principal produtora de amendoim onde, na safra 2017/18 teve produtividade de $3.704 \mathrm{~kg} \mathrm{ha}^{-1}$.

O amendoim é hoje um importante componente na produção industrial de doces, salgados e para seu consumo "in natura", visto que esta oleaginosa possui em torno de 22 a 30\% de proteína e alto teor de óleo nos seus grãos (RODRIGUES et al., 2016). Na pecuária, o amendoim pode servir tanto para grãos como para forragem, através do corte e desidratação da parte aérea para posterior obtenção de feno (GOMES; PERES; MITTELMANN, 2009).

Esta oleaginosa tem potencial para desenvolver-se ainda mais com pesquisas e investimentos relacionadas à distribuição das plantas na área, com a densidade adequada, contribuindo para melhores desempenhos da cultura tornando-a mais competitiva contra plantas daninhas e facilitando 0 manejo de máquinas agrícolas na área (SILVEIRA et al. 2010). Com isso, em função da densidade de semeadura, objetivou-se avaliar o crescimento inicial em altura $(\mathrm{cm})$, número de folhas e diâmetro $(\mathrm{mm})$ e diâmetro da haste principal de quatro cultivares de amendoim.

\section{Material e métodos}

O experimento foi conduzido no ano agrícola 2018/2019, no município de Garanhuns-Pernambuco (Agreste Meridional), com altitude de $828 \mathrm{~m}$ (EARTH, 2019). O solo da área experimental é classificado como Argissolo Amarelo, de textura franco-argilo-arenoso. Na região, o clima predominante é do tipo As', que equivale a um clima tropical com estação seca de verão e chuvosa de inverno, de acordo com a classificação de Köppen. A 
temperatura média é $20,4^{\circ} \mathrm{C}$ e a pluviometria anual é de $873 \mathrm{~mm}$ (CLIMATE, 2019).

A adubação para a cultura foi baseada na $5^{\mathrm{a}}$ aproximação de Ribeiro (1999) sendo realizada no momento da semeadura a aplicação de $40 \mathrm{~kg} \mathrm{ha}^{-1}$ de $\mathrm{P}_{2} \mathrm{O}_{5}$ e $60 \mathrm{~kg} \mathrm{ha}^{-1}$ de $\mathrm{KCl}$, não havendo adubação de cobertura. Para a fixação biológica do nitrogênio foi empregado via inoculação das sementes bactérias do gênero Bradyrizobium sp. comercial na proporção de 100 gramas para cada $40 \mathrm{~kg}$ de sementes.

Os tratos culturais, como capinas e controle de pragas e doenças, foram aplicados quando constatado por monitoramentos diários e amostragens. Quanto ao sistema de irrigação, o mesmo foi composto por mangueiras e microaspersores distribuídos na área.

O amendoim foi cultivado em condições de campo, em delineamento em blocos ao acaso, com três repetições, em esquema de subparcela de $4 \times 5$, ou seja, cultivares $\times$ densidades (tratamentos) onde, as cultivares foram Tatu ST e BR1 (crescimento vertical) e Runner IAC 886 e IAC 503 (crescimento prostrado). As densidades testadas foram de 8, 11, 14, 17 e 20 plantas $\mathrm{m}^{-1}$ de área útil. A semeadura foi feita de forma manual, com espaçamentos entrelinhas de $0,50 \mathrm{~m}$ e $0,80 \mathrm{~m}$ para as cultivares eretas e rasteiras respectivamente.

As avaliações foram realizadas na área útil, por meio das seguintes características agronômicas e utilizando a amostra de 10 plantas por parcela: Altura aos 28, 35 e 42 dias após a semeadura (DAS); Número de folhas aos 28, 35 e 42 dias após a semeadura (DAS); Diâmetro do caule aos 28, 35 e 42 dias após a semeadura (DAS).

Para o fator qualitativo, os dados foram submetidos à análise de variância e as médias comparadas pelo teste de Tukey (significância de 5\%), empregando-se o software SISVAR 5.3. Já para o fator quantitativo (densidade), foi utilizada a análise de regressão polinomial. 


\section{Resultados e discussão}

A figura $1(\mathrm{~A}, \mathrm{~B}$ e $\mathrm{C})$ contém o gráfico de altura, número de folhas e diâmetro de quatro cultivares de amendoim aos 28 dias após a semeadura. Para esta variável é possível notar que, quando se aumenta a densidade de plantas, a altura, o número de folhas e o diâmetro também aumentam, assim como em soja, devido a competições intraespecíficas, explica Mauad et al. (2010).
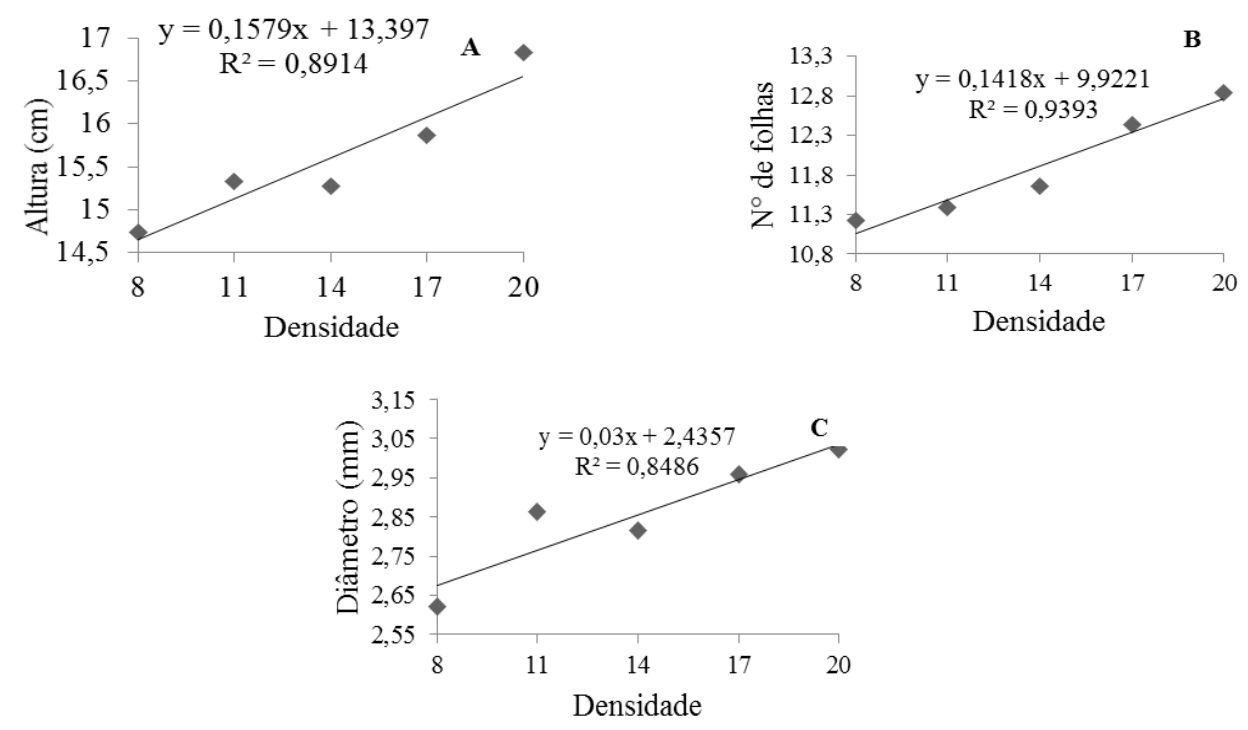

Figura 1. Altura (A), Número de Folhas (B) e Diâmetro (C) aos 28 Dias Após a semeadura (DAS) de quatro cultivares de amendoim (Runner IAC 886, IAC 503, BRI, e Tatu ST) submetidas a cinco densidades de semeadura. UFRPE-UAG, 2019.

Aos 35 dias após a semeadura (Figura 2) é possível observar que as plantas continuam respondendo aos efeitos do aumento da densidade de plantio, seguindo a mesma tendência do que ocorreu aos 28 DAS. Com isso, até os 35 DAP as plantas de amendoim ainda sofrem o efeito da competição intraespecífica. Bellettini \& Endo (2001), Nakagawa et al. (2000) também observaram o mesmo comportamento de aumento de altura em função do aumento das densidades na cultura. É possível que os fatores do ambiente como luz, temperatura e disponibilidade de água tenham potencializado o maior efeito da competição até este período por não atenderem as necessidades da cultura fazendo com que ela se ajustasse as condições oferecidas. 

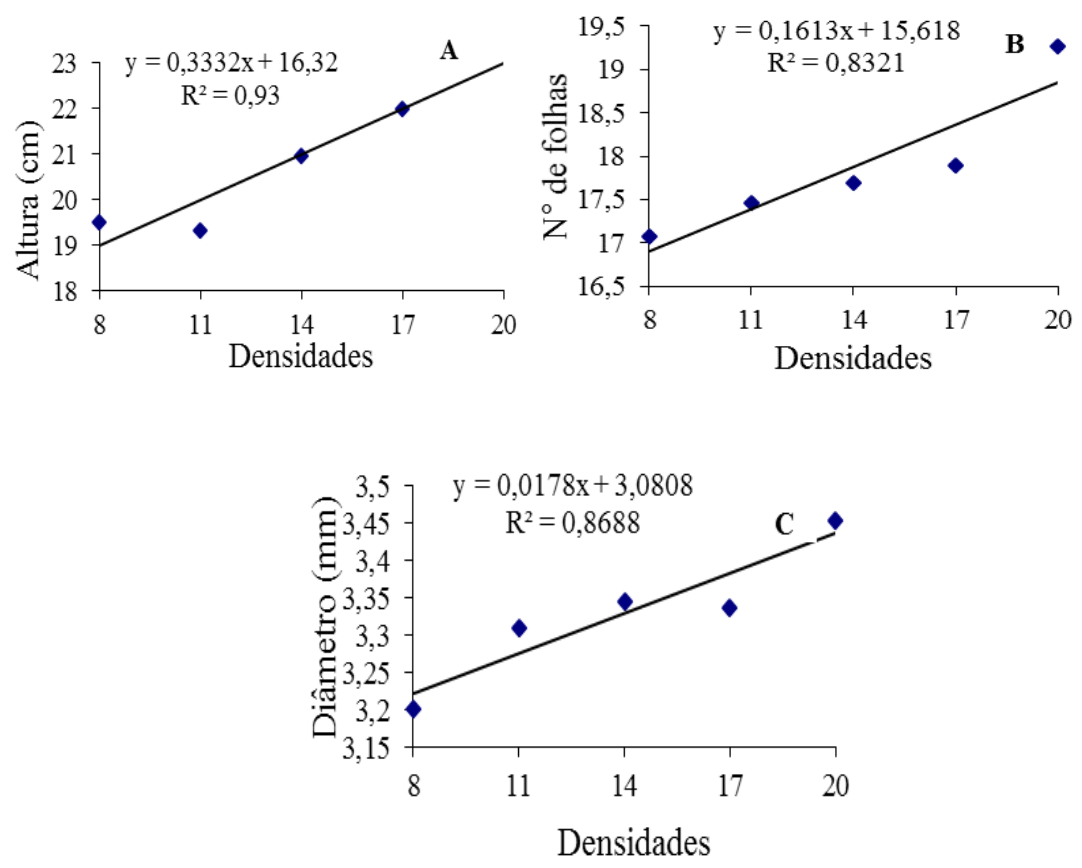

Figura 2. Altura (A), Número de Folhas (B) e Diâmetro (C) aos 35 Dias Após a Semeadura (DAS) de quatro cultivares de amendoim (Runner IAC 886, IAC 503, BRI, e Tatu ST) submetidas a cinco densidades de semeadura. UFRPE-UAG, 2019.

No período de 42 dias após a semeadura (Figura 3 A), nota-se que, de acordo com o aumento das densidades, as plantas só respondem aos estímulos de altura, porém tal comportamento não foi tão expressivo quanto aos 28 e 35 DAS. Quanto ao número de folhas (Figura 3 B) e o diâmetro (Figura $3 \mathrm{C}$ ), estes também não se desenvolveram quanto nas análises anteriores. Como essa época coincidiu com o início do florescimento, entende-se que as plantas já estão começando a estabilizar e direcionar sua energia para esta fase. Silveira (2010) em pesquisa de cultivares do grupo valência no recôncavo sul baiano constatou início do florescimento aos 43 dias após a semeadura.

Quanto aos dados da tabela 1, tem-se um resultado esperado quanto à altura para as cultivares de crescimento de ereto. As cultivares Tatu ST e BR1 apresentaram maiores médias de altura aos 28, 35 e 42 DAS 
em comparação com as cultivares de porte rasteiro (IAC 503 e IAC Runner 886), resultado inverso ao número de folhas.
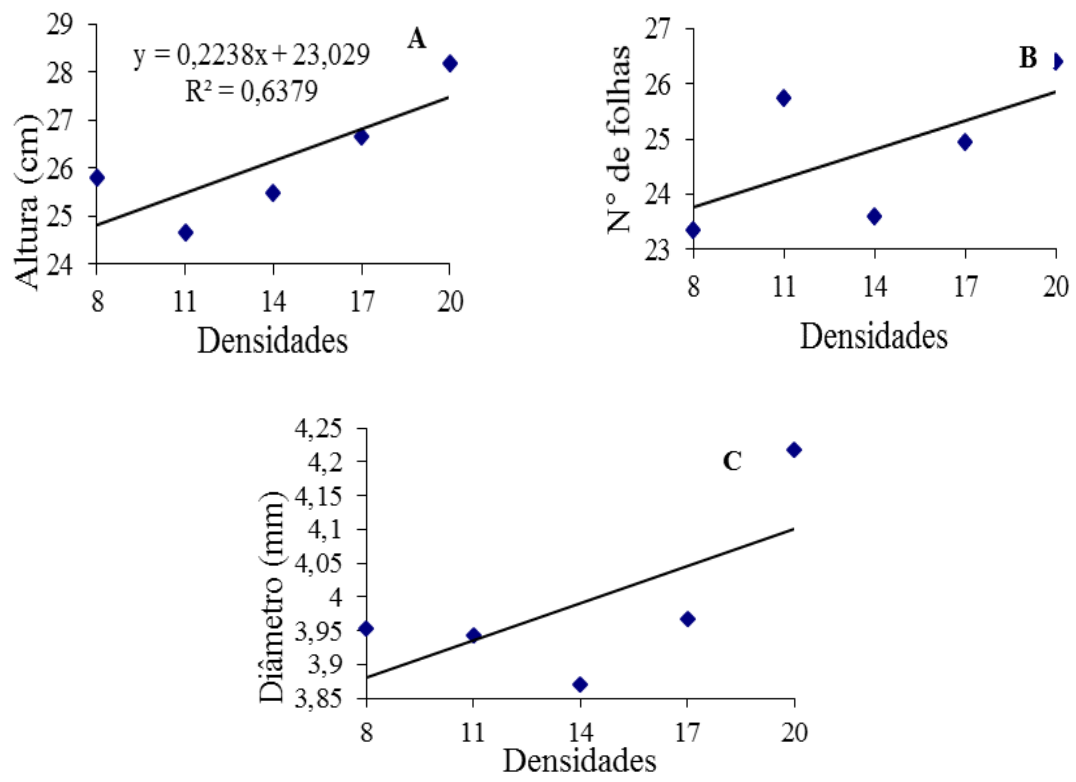

Figura 3. Altura (A), Número de Folhas (B) e Diâmetro (C) aos 42 Dias Após a semeadura (DAS) de quatro cultivares de amendoim (Runner IAC 886, IAC 503, BRI, e Tatu ST) submetidas a cinco densidades de semeadura. UFRPE-UAG, 2019.

Tabela 1. Altura $(\mathrm{cm})$, Número de folhas e diâmetro $(\mathrm{mm})$ da haste principal de quatro cultivares de amendoim aos 28, 35 e 42 Dias Após a Semeadura (DAS). Garanhuns, UFRPE-UAG, 2019.

\begin{tabular}{|c|c|c|c|}
\hline CULTIVAR & ALTURA AOS 28 DAS & $N^{\circ}$ FOLHAS AOS 28 DAS & $\begin{array}{l}\text { DIÂMETRO AOS } \\
28 \text { DAS }\end{array}$ \\
\hline IAC 503 & $14,43 \mathrm{~b}$ & $12 \mathrm{ab}$ & $2,7 \mathrm{~b}$ \\
\hline IAC 886 & $16,51 \mathrm{ab}$ & $14 \mathrm{a}$ & $2,5 \mathrm{~b}$ \\
\hline BR1 & $14,69 a b$ & $10 \mathrm{~b}$ & $3,1 \mathrm{a}$ \\
\hline TATU ST & $16,79 \mathrm{a}$ & $11 \mathrm{~b}$ & $3,2 \mathrm{a}$ \\
\hline CULTIVAR & ALTURA AOS 35 DAS & $\mathrm{N}^{\circ}$ FOLHAS AOS 35 DAS & $\begin{array}{l}\text { DIÂMETRO AOS } \\
35 \text { DAS }\end{array}$ \\
\hline IAC 503 & $17,98 \mathrm{~b}$ & $20 \mathrm{a}$ & $3,11 \mathrm{~b}$ \\
\hline IAC 886 & $20,55 \mathrm{~b}$ & $21 \mathrm{a}$ & $3,07 \mathrm{~b}$ \\
\hline BR1 & $21,02 \mathrm{ab}$ & $14 \mathrm{~b}$ & $3,41 \mathrm{ab}$ \\
\hline TATU ST & $24,39 a$ & $16 \mathrm{~b}$ & $3,73 \mathrm{a}$ \\
\hline CULTIVAR & ALTURA AOS 42 DAS & $\mathrm{N}^{\circ}$ FOLHAS AOS 42 DAS & $\begin{array}{c}\text { DIÂMETRO AOS } \\
\text { 42 DAS }\end{array}$ \\
\hline IAC 503 & $20,53 \mathrm{~b}$ & $28 \mathrm{a}$ & $3,77 \mathrm{a}$ \\
\hline IAC 886 & $23,73 \mathrm{~b}$ & $28 \mathrm{a}$ & $3,80 \mathrm{a}$ \\
\hline BR1 & $29,06 \mathrm{a}$ & $21 \mathrm{~b}$ & $4,25 \mathrm{a}$ \\
\hline TATU ST & $31,33 \mathrm{a}$ & $22 \mathrm{~b}$ & $4,15 \mathrm{a}$ \\
\hline $\begin{array}{l}\text { *Médias seguidas } \\
\text { probabilidade. }\end{array}$ & pela mesma letra m & las não diferem pelo teste & e Tukey, a $5 \%$ de \\
\hline
\end{tabular}


Já em relação ao diâmetro do caule, houve diferença significativa somente aos 28 e 35 DAS, sendo as cultivares de porte ereto apresentando maiores medidas, característica atribuída as cultivares devido ao seu hábito, não havendo diferença aos 42 DAS devido a uma possível estabilização e redirecionamento de energia para a fase reprodutiva da planta.

\section{Conclusões}

Aos 35 dias após a semeadura de amendoim, maiores valores de altura, número de folhas e diâmetro de plantas são obtidos com densidades de 17 e 20 plantas $\mathrm{m}^{-1}$ no agreste pernambucano. $O$ diâmetro de cultivares de porte rasteiro não se diferencia de cultivares de porte ereto aos 42 dias após a semeadura. 


\section{Referências}

BELLETTINI, Nair Mieko Takaki; ENDO, Romeu Munashi. Comportamento do amendoim das "águas", Arachis hypogaea L., sob diferentes espaçamentos e densidades de semeadura. Acta Science Agronomy. Maringá, v.23, n. 5, p. 1256, 2001.

CLIMATE.DATA.ORG. Dados climáticos para cidades mundiais: Disponível em: <https://pt.climate-data.org/america-dosul/brasil/pernambuco/garanhuns-4458/ . Acesso em: 16 jan. 2019.

COMPANHIA NACIONAL DE ABASTECIMENTO | ACOMPANHAMENTO DA SAFRA BRASILEIRA DE GRÃOS | v. 6 - Safra 2018/19, n.4 - Quarto levantamento, janeiro 2019. Disponível em: $<$ https://www.conab.gov.br/infoagro/safras/graos/boletim-da-safra-de-graos?start=10>. Acesso em: 15 de jan de 2019.

EARTH, GOOGLE. Disponível em: <https://earth.google.com/web/@$8.90873951,-$

$36.49640832,830.57813872 a, 39.22985131 d, 35 y, 0.00000001 \mathrm{~h}, 51.70507253 \mathrm{t}$ ,-Or $\geq$. Acesso em: 16 jan. 2019.

GOMES, Jorge Fainé; PERES, Milena Moreira; MITTELMANN, Andréa. Aptidão do amendoim para produção de forragem e grãos. Pelotas, RS: EMBRAPA- Clima Temperado, 2009. 2p. (Comunicado Técnico, 216).

INSTITUTO DE ECONOMIA AGRíCOLA - IEA, Governo do Estado de São Paulo. Análises e Indicadores do Agronegócio, v. 13, n. 3, março 2018. Disponível em: <http://www.iea.agricultura.sp.gov.br $\geq$. Acesso em 15 de jan de 2019.

MAUAD, Munir; SILVA, Thiago Leonel Bertoloze; ALMEIDA NETO, Antonio Inacio; ABREU, Vinicius Gomes. Influência da densidade de semeadura sobre características agronômicas na cultura da soja. Revista Agrarian, Dourados, v.3, n.9, p.175-181, 2010.

NAKAGAWA, João; LASCA, Dalmo de Campos; NEVES, Gessy de Souza; NEVES, João Paulo de Souza; SILVA, Maurício Nunes da; SANCHES, Sérgio Veraguas; BARBOSA, Valmir; ROSSETTO, Cláudia A. V. Densidade de plantas e produção de amendoim. Scientia Agrícola, Piracicaba, v.57, n. 1, p. 67 - 73, 2000.

RODRIGUES, Liliane Garcia da Silva Morais; RODRIGUES, Fernando Morais; OLIVEIRA, Elisa Maria de; VIERA, Vanessa Bordin ; ARÉVALO, Arturo Meléndez; VIROLI, Sérgio Luis Melo. Amendoim (Arachis sp.) como fonte na matriz energética brasileira. Journal of Bioenergy and Food Science, v.3, n.3, p.178-190, 2016. 
SILVEIRA, Patrícia Souza da. Época de semeadura e densidade de plantas em cultivares de amendoim no recôncavo sul baiano. 2010. $112 \mathrm{f}$. Dissertação (Mestrado em fitotecnia) - Universidade federal do recôncavo da Bahia. 